\title{
Paraísos fiscales: una línea de contradicción entre la formalidad y la materialidad
}

\author{
Hugo Marulanda Otálvaro* \\ LILIANA HEREDIA RODRÍGUEZ ${ }^{* *}$
}

Sumario: I. Introducción y objetivos de la investigación. 1. Objeto de la investigación. II. Los paraísos fiscales y el detrimento de la recaudación fiscal de los Estados. 1. Características de los paraísos fiscales. 2. Principales efectos lesivos de su existencia. III. La OCDE frente a los paraísos fiscales. 1. Primeros acercamientos. 2. Desarrollos posteriores (años 2000 a 2012). 3. Plan de acción BEPS. IV. Contradicción entre la formalidad y la materialidad. 1. La formalidad de los paraísos fiscales. 2. La materialidad de las cifras hacia los paraísos fiscales. 3. Reflexión sobre el estado actual de la cuestión. v. Conclusiones. Referencias.

\section{Resumen}

Organismos internacionales como la OCDE, la UE, el G7/G8 y el G20 han adelantado diversos estudios y trabajos para combatir y evitar la proliferación de vehículos fiscales opacos o fraudulentos como las prácticas fiscales perniciosas, los regímenes fiscales preferenciales y, en especial, los paraísos fiscales, todo ello con el ánimo de prevenir la erosión de la base imponible y la disminución de la recaudación fiscal que se ocasiona por el traslado de los beneficios empresariales a jurisdicciones de baja o nula tributación. Sin embargo, estos esfuerzos se han quedado bajo la línea de la formalidad, pues-

* Candidato a Doctor en Derecho, Universidad de Castilla-La Mancha, España; Magíster en Fiscalidad Internacional y Comunitaria, Planeación fiscal y auditoría fiscal; Magíster en Fiscalidad Internacional y Comunitaria, Derecho Tributario, Universidad de Castilla-La Mancha. Docente investigador Universidad Pontificia Bolivariana, Medellín, Colombia. Para citar el artículo: Marulanda, H. \& Heredia, L. (2016). "Paraísos fiscales: una línea de contradicción entre la formalidad y la materialidad". Revista de Derecho Fiscal n. 8 , Bogotá: Universidad Externado de Colombia. pp. 131-155.

** Doctoranda y Magíster en Análisis económico del Derecho y Políticas públicas, de la Universidad de Salamanca, España; Especialista en Legislación tributaria, de la Universidad Pontificia Bolivariana, y Contadora Pública de la Universidad del Quindío. Docente de la Pontificia Universidad Javeriana, de Cali. Correo-e: lilianaheredia@javerianacali.edu.co.Para citar el artículo: Marulanda, H. \& Heredia, L. (2016). "Paraísos fiscales: una línea de contradicción entre la formalidad y la materialidad". Revista de Derecho Fiscal n. ${ }^{\circ}$, Bogotá: Universidad Externado de Colombia. pp. 131-155. DOI: http://dx.doi.org/10.18601/16926722.n8.10 
to que en la línea de la materialidad persisten la planificación fiscal agresiva, el secreto bancario y la opacidad en el intercambio de información financiera y tributaria.

\section{Introducción}

Algunos operadores económicos vienen depositando cada vez mayor cantidad de fondos en los paraísos fiscales sin que las organizaciones internacionales, que por naturaleza han luchado contra ellos, adelanten trabajos efectivos para erradicarlos. Parece que se han congelado en el tiempo aquellos plausibles trabajos de la Organización para la Cooperación y el Desarrollo Económicos (OCDE), debido a que varios de sus Estados miembros cuentan con territorios dependientes conocidos como paraísos fiscales y, por consiguiente, no tendrán intereses políticos ni económicos en su desmantelamiento.

Dichos intereses han llevado a la eliminación, por parte de la OCDE, de uno de los principales criterios para identificar a los paraísos fiscales: el desarrollo de actividad económica sustancial en dichos territorios, argumentando la potestad tributaria de cada Estado. En su lugar, se estableció la suscripción de mínimo 12 acuerdos de intercambio efectivo de información con otros Estados o territorios dependientes, como criterio para ser retirados de la lista negra de paraísos fiscales, lo cual es solo una distracción internacional.

Lo anterior nos lleva a reflexionar sobre la efectividad real de dicho criterio. Aunque formalmente no existen Estados o territorios dependientes en la lista negra de paraísos fiscales, al cumplir con dicha directriz, materialmente, lo que podemos constatar es que estos siguen existiendo y operando. Entre otros, autores como Zucman, García Noriega e informes de las organizaciones no gu- bernamentales (ONG) Tax Justice Network e Oxfam-Intermón y del Consorcio Internacional de Periodistas de Investigación (ICIJ, por sus siglas en inglés) confirman el auge de los paraísos fiscales, el secreto bancario y la opacidad en el intercambio de información financiera y tributaria (Zucman, 2014, 150; García Noriega, 2014, 471; Oxfam, 2015).

\section{Objeto de la investigación}

La presencia de una fuerte contradicción entre la formalidad y la materialidad de los paraísos fiscales nos motiva para desarrollar esta investigación de tipo jurídico, en la cual no pretendemos ahondar en su génesis, definiciones doctrinales o clases, temas tratados con amplitud por doctrinantes, organizaciones internacionales, Agencias Tributarias, ONG e investigadores. Nuestra investigación aborda de manera objetiva la contradicción existente entre la formalidad y la materialidad de los paraísos fiscales, con el fin de plantear una reflexión crítica en relación con la existencia de dichos territorios.

Como se ha mencionado, la lista negra de la OCDE ya no contiene ningún paraíso fiscal. Sin embargo, encontramos que es frecuente el desplazamiento de capitales a estos territorios con baja o nula tributación o cuyo intercambio de información es nulo o ineficiente, y donde se crea un ambiente propicio para la elusión y la evasión fiscales en menoscabo de las finanzas de los Estados, que deben afrontar como mínimo tres problemas (Fischer, 2014, 338). En primer lugar, dejan de percibir el justo pago de los tributos; en segundo lugar, asumen los costes por el uso de los recursos, la infraestructura y los servicios públicos por parte de aquellos contribuyentes que físicamente no se han trasladado de sus Estados de origen y, en ter- 
cera instancia, deben invertir mayor cantidad de recursos en la persecución de los evasores.

\section{Los paraísos fiscales y el detrimento de la recaudación fiscal de los Estados}

\section{Características de los paraísos fiscales}

Podemos inferir que las características (principales y auxiliares) de los paraísos fiscales están reflejadas en el informe de la OCDE sobre competencia fiscal perniciosa de 1998, las cuales deben concurrir de manera simultánea para que un Estado, jurisdicción o territorio sea considerado como un paraíso fiscal (OCDE, 1998, 22). Las características a examinar son: 1) un nivel de tributación bajo o nulo, 2) falta de transparencia, especialmente en la aplicación del sistema fiscal, 3) falta de intercambio efectivo de información, y 4) inexistencia de actividad económica sustancial en su jurisdicción. Estas características también han sido analizadas por autores como Vallejo, Ferre, Martín y Marulanda, quienes hacen especial referencia a la eliminación de las características uno y cuatro, debido a la presión ejercida por algunos Estados miembros de la OCDE, como se amplía más adelante (Vallejo Chamorro, 2007, 220); (Ferre Navarrete en Cordón Ezquerro, 2007, 1658; Rodríguez, en Collado Yurrita, 2005, 676; Marulanda Otálvaro, 2013, 36).

El citado informe incluye los siguientes criterios auxiliares para identificar a las jurisdicciones constitutivas de paraísos fiscales: definiciones artificiales de base imponible; falta de aplicación de los criterios sobre precios de transferencia elaborados por la OCDE; existencia de exención a las rentas de fuente extranjera; la posibilidad de negociación, con las autoridades fiscales, de las condiciones de imposición o rulings, y la fama internacional reluciente de la jurisdicción como paraíso fiscal o la existencia de autopublicidad o reputation test.

Desde la doctrina también es posible apreciar algunas características atribuibles a los paraísos fiscales, entre ellas, bajos o nulos impuestos para no residentes; existencia del secreto bancario y comercial establecido mediante la ley; legislación financiera y comercial atractiva; deficiencias en la supervisión y control bancario; carencia de informaciones y estadísticas completas sobre las operaciones financieras; inexistencia de control de cambios y libertad total de movimiento de capitales; regulación y control administrativos escasos; sistema jurídico flexible y con frecuencia diferente para residentes y no residentes; volumen de operaciones financieras de no residentes, en moneda no local, desproporcionado con relación a la economía local, y presencia de estabilidad política y económica (Martínez Selva, 2009, 27; Hernández Vigueras, 2005, 45; Schejelderup, 2015, 4).

Infortunadamente, el trabajo adelantado por la OCDE para la identificación de los paraísos fiscales ha quedado rezagado con la eliminación de los dos criterios antes mencionados, los cuales representan elementos clave para la calificación como tal ante la comunidad internacional. Frente a este aspecto, señala Hernández Vigueras:

[e]n la identificación de un paraíso fiscal desempeña una función de primer orden la ausencia de obligación de ejercer una actividad sustancial para la obtención de los beneficios fiscales, puesto que los esfuerzos para atraer las inversiones y las operaciones financieras se justifican exclusivamente en razones fiscales. Probablemente se manifieste también en el hecho de que estos 
países o territorios no ofrezcan un entorno comercial o ventajas efectivas que atraigan verdaderas actividades industriales y comerciales ante las favorables posibilidades fiscales. Y hasta es posible que en la práctica pueda resultar difícil definir una actividad sustancial tratándose de servicios financieros y de gestión; por tanto, para determinar la existencia de este elemento definitorio en el documento de la OCDE se prevé la realización de evaluaciones (Hernández Vigueras, 2005, 61).

Es precisamente sobre este asunto que queremos enfatizar en nuestro trabajo, teniendo en cuenta que formalmente la lista negra de paraísos fiscales se ha reducido a cero ante la facilidad de satisfacer los dos criterios de compromisos políticos de intercambio efectivo de información y transparencia de los sistemas fiscales. Criterios que se cumplen mediante la suscripción de acuerdos que permiten a un territorio su reivindicación teórica como una jurisdicción transparente y con libre competencia fiscal, cuando en la práctica se incrementan cada vez más las inversiones y las sociedades de papel en dichas jurisdicciones, gracias a que los principales Estados miembros de la OCDE cuentan con territorios asociados, que actúan como plenos paraísos fiscales, dejando en evidencia que priman los intereses políticos y económicos de unos pocos sobre los intereses de transparencia fiscal (Hernández Vigueras, 2005,59; Schejelderup, 2015, 2; Gravelle, en Congressional Research Service, 2015, 7).

\section{Principales efectos lesivos de su existencia}

Muchas son las consecuencias nocivas que los paraísos fiscales han ocasionado y seguirán generando mientras la normativa para hacerles frente siga siendo tan flexible y no se tomen medidas reales y efectivas para combatirlos. Entre ellas, y a manera de ejemplo, se puede mencionar Martín López $(2006,47)$.

Permiten el desvío de la carga fiscal de las actividades móviles, como la financiera, hacia sectores menos móviles como la producción industrial; de la menor tributación sobre el capital hacia la mayor tributación del trabajo y de las actividades de consumo, generando distorsión de los flujos financieros y las inversiones productivas reales, lo que a su vez ocasiona una localización ineficiente de los recursos financieros al socavar la integridad y la equidad de las estructuras fiscales.

1) Desincentivan el cumplimiento de las obligaciones tributarias, condicionando la política fiscal de los Estados y, por consiguiente, el mantenimiento y la supervisión de los sistemas de protección social de los países.

2) Contribuyen a la desestabilización del sistema financiero.

3) Ocasionan disminución de la recaudación fiscal de los Estados y, por consiguiente, minan la capacidad de estos para realizar inversión social, y mejorar la infraestructura y los servicios públicos. Este efecto es más intenso en los países en vías de desarrollo que en los países desarrollados.

4) Constituyen un refugio seguro para la delincuencia financiera internacional, los políticos corruptos y para el blanqueo de capitales.

Las afirmaciones anteriores se corresponden con los planteamientos de distintos autores y organismos internacionales, quienes coinciden en que las cifras son difíciles de cuantificar y los datos pueden variar según 
las fuentes, pero siguen siendo significativos. A manera de ejemplo, mencionamos las siguientes cifras: se estima que debido a los paraísos fiscales, los países en desarrollo dejan de percibir impuestos por unos 50.000 USD millones anuales (FMI, 2011, 39); que por estos territorios circula la mitad del comercio mundial (unos siete billones de dólares) de los sectores financieros y entre 600.000 y 1,5 billones de dólares de dinero negro (Vallejo Chamorro, 2007, 149), y que del patrimonio financiero de las familias, el $8 \%$ a escala mundial y el $12 \%$ en la Unión Europea (UE) está guardado en los paraísos fiscales (Zucman, 2014, 11). Así mismo, se calcula que hubo una recuperación por parte de 20 países, de 14 mil millones de euros provenientes de más de 100.000 contribuyentes que poseían en el extranjero bienes no declarados (Gurría en Foro Global sobre transparencia e intercambio fiscal, 2011).

Consideramos que los paraísos fiscales suscitan sobre muchos Estados una ruptura del principio de justicia fiscal, al incidir en que los contribuyentes con rentas menos móviles (como los trabajadores, las inmobiliarias y las pequeñas y medianas empresas) asuman una mayor carga fiscal para compensar el déficit interno, generado por la deslocalización o el traslado de inversiones y riqueza a los paraísos fiscales (Rosembuj, 2012, 65) (Rixen, 2011, 447). Debido a este tratamiento inequitativo, los contribuyentes que asumen mayor presión fiscal no ven compensado su esfuerzo financiero porque todos los operadores económicos se beneficiarán por igual de las políticas públicas, con independencia de su mayor o menor contribución fiscal. Los regímenes tributarios preferenciales que contribuyen a la erosión de la base imponible no solo impactan en la disminución de los ingresos públicos, sino que afectan la equidad del sistema tributario, socavan la confianza de los contribuyentes en su integridad y distorsionan el comercio y la inversión (UN, Chapter VII Fiscal Space for Stability and Development, 2014, 193).

\section{La OCDE frente a los paraísos fiscales}

\section{Primeros acercamientos}

Los paraísos fiscales constituyen una forma abierta y directa de permear la competencia fiscal interestatal, motivo por el cual generan la preocupación de todos los países, principalmente de aquellos más desarrollados, por la disminución de la recaudación fiscal y la erosión de la base imponible internacional, lo que ha alentado el interés (hasta ahora formal) de la OCDE, el G7/G8 (antes G8 con Rusia que está suspendido desde 2014) y el G20 para trabajar de manera mancomunada en la lucha contra estos, en pro de la protección de las finanzas públicas de los países y principalmente de sus Estados miembros.

En un primer informe que data de 1987, la OCDE subrayó las dificultades encontradas para definir de modo objetivo qué es un paraíso fiscal. Por tanto, en ese momento se acogió el "criterio de la reputación", que consistía en calificar como paraíso fiscal aquel territorio que desempeñara ese papel o se presentara o fuera reconocido generalmente como tal. Once años después, en su informe hito sobre competencia fiscal perjudicial de 1998, denominado "Competencia fiscal perjudicial: una cuestión global emergente" (o en inglés Harmful Tax Competition. An Emerging Global Issue), logra 
una definición técnica de paraíso fiscal, acordando los criterios que definen a efectos fiscales esta condición, aunque ello no resolviera el problema de la identificación de los paraísos fiscales ((Hernández Vigueras, 2005, 59); (Carrasco en Collado Yurrita, 2011, 363) (Marulanda Otálvaro, 2013, 49).

Aunque en ese momento se creó el grupo de trabajo responsable de supervisar la correcta implementación de las recomendaciones consideradas en el informe, especialmente las cláusulas standstill y rollback; denominado "Foro de Competencia Fiscal Perjudicial" (en inglés Forum on Harmful Tax Practices), se establecieron diversas recomendaciones y se definió la evaluación periódica de los resultados en el encuentro mundial del Foro Global sobre la transparencia e intercambio de información con fines fiscales (en adelante Foro Global). A fecha de hoy no se ha logrado un avance significativo, lo que podría atribuirse en gran medida a la falta de voluntad política y de compromiso real de los Estados miembros para la total eliminación de estas jurisdicciones de la esfera económica mundial.

El informe de la OCDE de 1998 es su trabajo cúspide, que abandera los posteriores informes y acciones en contra de los paraísos fiscales, que han sido flexibilizados al liberar algunos de sus principales criterios, lo que constituye un declive en tan abultado esfuerzo. Dicho informe fue aprobado en el mismo año por todos sus Estados miembros, con excepción de Luxemburgo y Suiza (Martín López, 2006, 66) y tanto este como los trabajos posteriores se constituyen en meras recomendaciones que son acogidas por voluntad política y no de manera obligatoria. Sobre el particular, señala el tratadista Martínez Selva: (a)sí, Luxemburgo aduce, fundamentalmente, la restricción del ámbito objetivo del informe -tal como podrá comprobarse seguidamente- a las actividades financieras, con la consiguiente exclusión de las propiamente industriales y comerciales, efectuándose, por ende, un estudio parcial y desequilibrado que, a su juicio, no busca tanto hacer frente al fenómeno de la competencia fiscal perjudicial como, en puridad, abolir el secreto bancario. Razonamiento éste completamente compartido por Suiza, la cual denuncia, igualmente, el craso error que significa tomar, como uno de los criterios identificativos de los regímenes fiscales preferenciales perniciosos, la existencia de una tributación menor en comparación a la fijada en el resto de los países, puesto que, a su parecer, ello ataca la soberanía de cada Estado para determinar su sistema fiscal y constituye una inaceptable protección de los países con altos niveles impositivos. En última instancia, tanto Luxemburgo como Suiza hacen constar taxativamente su no vinculación por el contenido del informe (Martínez Selva, 2009, 252).

En el citado informe, se emiten recomendaciones para que los Estados identificados como poseedores de una competencia fiscal perjudicial (sea como paraísos fiscales o a través de regímenes fiscales preferenciales) hagan las modificaciones necesarias en sus sistemas fiscales o a través de convenios bilaterales para evitar la doble imposición internacional o de cooperación multilateral de carácter internacional. De las diecinueve recomendaciones, clasificadas en tres categorías (OCDE, 1998, 40), abordaremos aquellas dirigidas de manera directa a los paraísos fiscales. 
1) En relación con la legislación interna, se propone limitar el método de exención de las rentas de fuente extranjera aplicados por ciertos Estados para eliminar la doble imposición, aplicar los principios en materia de precios de transferencia elaborados por la OCDE y remover los obstáculos que impiden el acceso de las autoridades tributarias de terceros Estados a la información bancaria de trascendencia fiscal.

2) Respecto de los convenios para evitar la doble imposición, se sugiere desarrollar programas de intercambio efectivo de información sobre actividades económicas radicadas en paraísos fiscales o en jurisdicciones con regímenes tributarios preferenciales; elaborar una lista que incorpore las entidades o tipos de rentas que deben quedar excluidas de los beneficios establecidos en el convenio, y permitir la terminación de un convenio y la no suscripción de convenios futuros en el supuesto de que una de las partes se repute como paraíso fiscal a la luz del informe.

3) En cuanto a la cooperación multilateral, la OCDE plantea la implementación, por parte de los Estados, de una completa guía que incorpora, entre otros aspectos, la creación de una lista de paraísos fiscales, el uso de las reglas de precios de transferencia y la necesidad de que los países que poseen vínculos políticos o económicos con paraísos fiscales garanticen la adopción de medidas para evitar que dichos vínculos contribuyan al incremento de la competencia fiscal perjudicial.

\section{Desarrollos posteriores}

(años 2000 a 2012)

En este apartado, abordaremos los aspectos más significativos de los avances presentados por la OCDE en sus informes desde 2000 hasta 2012, orientados a con- trarrestar la problemática de los paraísos fiscales. En el "Informe de Progreso en la Identificación y Eliminación de Prácticas Fiscales Perjudiciales" (OCDE, Eliminating Harmful Tax Practices, 2000), se presentó la lista de Estados catalogados como verdaderos paraísos fiscales, incluidos también los Estados miembros de la OCDE o sus territorios asociados, que fueron identificados como regímenes fiscales preferenciales potencialmente perniciosos. Del grupo inicial de 41 jurisdicciones, solo fueron publicadas 35 como paraísos fiscales (Hernández Vigueras, 2005, 62). Las seis restantes consiguieron salir de este listado gracias a su compromiso público de eliminar o modificar las normas jurídico-fiscales que precisaran un carácter pernicioso en un plazo concreto (31 de diciembre de 2005). Los Estados que no fueron incluidos en dicha lista fueron Bermudas, Chipre, Islas Caimán, Malta, Mauricio y San Marino, que se comprometieron anticipadamente a corregir sus sistemas fiscales con carácter pernicioso.

Desde el seno de la OCDE se buscaba que los paraísos fiscales suprimieran de sus sistemas tributarios aquellas prácticas y normas perniciosas para eliminarlos de la famosa lista negra. De modo que se señalaron como pautas para los trabajos futuros, en primer lugar, que los trabajos de evaluación se plantearían con sentido dinámico, es decir, un paraíso fiscal podría comprometerse a abandonar dicha lista en el momento que lo considerara oportuno para sus propios intereses y, en segundo lugar, se reforzaría la voluntad de diálogo con las jurisdicciones cooperantes, por lo que se trabajaría en cuatro líneas (Vallejo Chamorro, 2007, 152): 1) la elaboración de un modelo de acuerdo para el intercambio de información, 2) la creación 
de un mecanismo multilateral de consulta con estas jurisdicciones, 3) la realización de asistencias técnicas y 4) el refuerzo de las administraciones fiscales.

Como hemos expuesto supra, más que las dificultades técnicas, fueron los intereses político-económicos los que entorpecieron el trabajo de la OCDE para identificar y calificar a determinados territorios como paraísos fiscales, así como para la implementación de las medidas defensivas propuestas por esta organización como estrategia para lograr que los paraísos fiscales abandonen sus prácticas perniciosas, siendo evidente una vez más que la creación de normas cuyo criterio de adopción responde a la voluntad de los Estados y no a un carácter vinculante ha sido ineficiente en la lucha contra la competencia fiscal perjudicial.

En 2001, la OCDE abandona uno de los criterios fundamentales para catalogar a los paraísos fiscales (la carencia de actividad sustancial) (OCDE, Project on Harmful Tax Practices, 2001), flexibilizando los requisitos a cumplir para desaparecer de la lista negra, lo que no constituye un avance sino un retroceso. En posición de Martín López (2006, 231):

[t]odo ello supone, a nuestro parecer, una auténtica regresión en la iniciativa de la OCDE contra la competencia fiscal perjudicial, al limitarse, en buena parte, su campo de actuación en materia de paraísos fiscales. Ciertamente, la amplia interpretación dada al factor de la falta de actividad económica sustancial había posibilitado, hasta este momento, la determinación como paraísos fiscales de aquellos Estados o jurisdicciones cuyos regímenes tributarios privilegiados tuviesen a los no residentes como únicos destinatarios.
El criterio eliminado fue reemplazado por el de creación de sistemas transparentes y con un intercambio efectivo de información, elementos que se consideraban suficientes para catalogar a un Estado como una "jurisdicción cooperante”. Así mismo, se ampliaron los plazos para que las jurisdicciones interesadas dispusieran de un término razonable para cumplir los requisitos establecidos. Esto contribuyó para que la mayoría de los hasta entonces paraísos fiscales de la lista negra asumieran el compromiso político y empezaran los ajustes de sus sistemas fiscales para abandonar su carácter pernicioso y salir así de dicha lista, cometido alcanzado casi por todos en ese momento, exceptuando a Andorra, Islas Marshall, Liberia, Liechtenstein, Mónaco, Nauru y Vanuatu (estos dos últimos lograron su exclusión del listado en 2003).

Con lo señalado hasta el momento, no pretendemos, de ninguna manera, restar importancia al intercambio de información como mecanismo que contribuye a la eliminación de la competencia fiscal perjudicial, sino insistir en que este requisito debería ser subsidiario de otros más exigentes. De hecho, concordamos con el planteamiento de Merino Espinosa y Nocete Correa (2011, 140), en relación con que el intercambio de información favorece la correcta aplicación de los regímenes tributarios y constituye una herramienta fundamental para las administraciones tributarias y para los propios contribuyentes interesados en la correcta determinación de sus deudas fiscales.

En el tercer informe de la OCDE (Project on Harmful Tax Practices, 2004), se empezó a utilizar el término socios colaboradores o socios participantes (en inglés participating partners) en lugar de paraísos fiscales, dejando este último reservado para 
las jurisdicciones no cooperantes, al considerar que los socios colaboradores estaban comprometidos con los principios de transparencia e intercambio efectivo de información contenidos en el "Modelo de acuerdo de intercambio de información de carácter fiscal" aprobado en 2002. La OCDE fomentó el establecimiento del "terreno de juego equilibrado" (level playing field) mediante el cual se busca garantizar la igualdad para la aplicación de los principios mencionados. Este concepto abarca tres frentes: la acción unilateral, por medio de la cual los Estados o territorios dependientes debían acoger los estándares internacionales definidos por la OCDE, en lo que respecta a los principios de transparencia e intercambio efectivo de información tributaria; acciones bilaterales, representadas en la suscripción de acuerdos para garantizar el cumplimiento de los principios indicados en la acción unilateral y, por último, acciones multilaterales, que fueran llevadas a cabo por diferentes jurisdicciones o territorios dependientes en conjunto y, sobre todo, resaltando la prioridad de garantizar aplicación de los principios indicados en la acción unilateral, que a su vez constituyen los únicos criterios para calificar a una jurisdicción como paraíso fiscal (Lampreave Márquez, 2010, 102).

En el informe presentado en 2006 y cuya extensión era de escasas seis páginas, la OCDE se centró en verificar y revisar que todas las jurisdicciones estuvieran cumpliendo sus compromisos adquiridos, además de mantener el diálogo y las negociaciones con todas las jurisdicciones para conseguir su adhesión a los estándares internacionales en esta materia. Para ello, se propuso impulsar la firma de acuerdos bilaterales de intercambio de información, siguiendo el modelo aprobado en 2002. Es de suponer que la brevedad de este informe se corresponde con la decisión de proseguir con el plan de acción de las tres fases establecidas en 2004, lo que resultaría lógico y congruente (OCDE, Project on Harmful Tax Practices, 2006).

En 2007, a raíz del diálogo y las negociaciones permanentes con las jurisdicciones consideradas paraísos fiscales, la lista negra se redujo de cinco a tres, una vez que Liberia e Islas Marshall se comprometieron a realizar las correcciones necesarias en sus sistemas fiscales, logrando su inclusión en la lista de "jurisdicciones cooperantes" (Marulanda Otálvaro, 2013, 69). Sólo quedan a esta fecha en la lista negra: Andorra, Liechtenstein y Mónaco. En 2009, Andorra, Liechtenstein y Mónaco consiguen salir de la lista negra, quedando esta sin ninguna jurisdicción perniciosa. A partir de ese momento, el trabajo para el Foro Global se enfoca en la permanente revisión, aprobación y recomendación para la implementación de las normas internacionales de transparencia e intercambio efectivo de información, con el fin de lograr una cooperación fiscal adecuada entre los Estados y el seguimiento a quienes incumplan con dicho compromiso.

Es también en 2009 cuando se "declara la guerra" a los paraísos fiscales y, por solicitud del G20, el Foro Global continúa sus trabajos para evitar la evasión fiscal, fomentando la utilización de instrumentos multilaterales a través del intercambio efectivo de información y la transparencia de los sistemas fiscales (OCDE, A Process for Achieving a Global Level Playing Field, 2004). Esta tarea rinde sus primeros frutos y en el informe de 2010 sobre los resultados de la implementación de los estándares internacionales de intercambio de información en materia tributaria fueron aprobados ocho de ellos en su marco jurídico y normativo (Bermudas, Botswa- 
na, Islas Caimán, Jamaica, India, Mónaco, Panamá y Qatar), en la fase I de recomendaciones, advirtiéndose que, previamente al inicio de la fase II de revisión, Panamá y Qatar tenían que responder adecuadamente a las recomendaciones efectuadas.

El dato destacado en el informe es que más de 30 jurisdicciones estaban negociando más de 150 acuerdos de intercambio de información fiscal. Sin embargo, esta cifra carece de verdadero valor cuando se constata que gran parte de los acuerdos suscritos por los paraísos fiscales durante 2009 por presión del G20 fueron firmados precisamente con otros paraísos fiscales (Johannesen \& Zucman, 2014, 70). Adicionalmente, si se tiene en cuenta que los acuerdos de intercambio de información son fundamentalmente bilaterales y no exigen que tal intercambio sea automático sino a petición, se configura el escenario perfecto para que los evasores simplemente trasladen sus fondos de un paraíso fiscal que tenga acuerdo con su país de origen hacia otro que no lo tenga (Winkleman, 2014, 201; Johannesen \& Zucman, 2014, 67).

En 2011, se notaron algunos progresos en la aplicación de las normas internacionales de intercambio de información en el ámbito fiscal propuestos por el G20 a la OCDE dos años antes. Se resaltó la pertinencia del apoyo de asistencia técnica a los países en desarrollo y a pequeñas jurisdicciones a efecto de conseguir una cooperación efectiva en materia tributaria. Aunque el objetivo inicial era lograr 60 informes de cumplimiento para el G20 de noviembre de 2011 y 70 para mayo de 2012, en 2011 se habían logrado 34.

Entrando ya en 2012, observamos que la OCDE mantiene su objetivo fundamental de asegurar que todas las jurisdicciones se adhieran a los mismos estándares de coope- ración internacional en materia fiscal tanto en la transparencia de sus sistemas fiscales como en el intercambio efectivo de información, buscando con ello contrarrestar la evasión transfronteriza que se hace más fácil con la liberalización de los mercados (OCDE, Global Forum on Transparency and Exchange of Information for Tax Purposes, 2012). En este mismo año, cuando se celebró el Foro Global, el G20 y la Declaración de Ministros de Finanzas y de Gobernadores de Bancos Centrales hicieron un llamamiento a todos los países a suscribir el Convenio Multilateral de Asistencia Mutua (OCDE, Global Forum on Transparency and Exchange of Information for Tax Purposes, 2012, Anexo III). Así mismo, se acordó que el Foro Global debería proporcionar un marco esencial para el trabajo en materia de transparencia e intercambio de información a efectos fiscales, y que debería incluir una función de vigilancia, combinada con un mayor desarrollo de los términos de referencia y la reciprocidad de las mejores prácticas de la experiencia de los incrementos de intercambio de información que, según la Entidad, sigue evolucionando de manera favorable.

\section{Plan de Acción BEPS}

Desde 2013 no se evidencian informes similares a los previamente referidos. Sin embargo, no se trata de que se haya desistido en el intento por combatir a los paraísos fiscales, sino que se ha reorientado hacia el Plan de Acción contra la Erosión de la Base Imponible y el Traslado de Beneficios, más conocido como el Plan de Acción BEPS (en inglés Base Erosion and Profit Shifting), el cual cuenta con el pleno respaldo del G20. En esta iniciativa se proponen 15 acciones; no obstante, en el caso concreto de este 
estudio, nos centramos en las acciones número uno (abordar los retos de la economía digital para la imposición) y número cinco (combatir las prácticas tributarias perniciosas, teniendo en cuenta la transparencia y la sustancia). Es oportuno indicar que estas acciones en su conjunto son retadoras pero su efectividad dependerá también de la mera liberalidad de los Estados, es decir, acciones no vinculantes que hasta ahora han carecido de efectividad para la erradicación de los paraísos fiscales, lo que hará que continúe presentándose el mismo choque de intereses que se ha evidenciado en las iniciativas anteriores entre quienes promueven la eliminación material de la competencia fiscal perjudicial y algunos Estados miembros de la OCDE, que solo promueven su eliminación formal porque están claramente ligados a los paraísos fiscales o centros de servicios financieros offshore. Este ambicioso proyecto se propone afrontar diversos problemas asociados a la fiscalidad, como son la economía digital, el establecimiento de estándares internacionales para el intercambio automático de información, el establecimiento permanente, la competencia fiscal y las operaciones con vinculados o reglas de precios de transferencia. Sin embargo, sorprende que ante tal amplitud no incorpore por ejemplo el problema de la residencia fiscal.

La idea original presentada en febrero de 2013 era una iniciativa plausible en la que se proponía la evaluación global de las normas fiscales internacionales. En ella, el cuestionamiento de la OCDE era por qué un modelo con más de 100 años de normas fiscales internacionales y generador de conceptos tan valiosos como el establecimiento permanente y capaz de lograr la multiplicación de los convenios para evitar la doble imposición, se había vuelto difícilmente conciliable con los modelos de negocios internacionales en una economía global, generando lo que conocemos como problemas de competencia fiscal, abuso de los tratados y rompimiento de los principios de fuente y de residencia. Sin embargo, en julio de 2013, cuando se formula el plan de acción, la propuesta inicial ya se había desviado de su objetivo original y se dio el salto a un plan de 15 acciones que recae en el mismo problema de las acciones previas desarrolladas por la OCDE, es decir, desde la formalidad se atacan la falta de transparencia, la elusión y la evasión, pero no se crean los instrumentos necesarios para que sus estrategias sean materialmente aplicables y, por tanto, es cuestionable su eficacia como alternativa para solucionar los problemas de recaudación que afrontan los Estados. En nuestra opinión, este proyecto no representa una solución real para enfrentar la planificación fiscal agresiva, entre otras cosas porque ha eludido conscientemente el problema de fondo que es la adecuación de un sistema de tributación internacional en el que se consideren temas centrales como la residencia fiscal y la potestad tributaria para distribuir correctamente la recaudación.

La iniciativa BEPS, pese a los problemas ya mencionados, tiene aspectos positivos y por ende, dignos de mencionar. El primero de ellos es el avance en materia de intercambio efectivo de información. El segundo, el reconocimiento de un fracaso de los sistemas de tributación internacional basados en los acuerdos bilaterales que interactúan con los sistemas tributarios internos, los cuales difícilmente pueden evitar la doble imposición sin crear de manera simultánea oportunidades de no imposición, siendo destacable la nueva estrategia orientada a los acuerdos multilaterales. Un tercer aspecto favorable del Plan BEPS es su retorno al requisito de la 
actividad sustancial que formaba parte del informe de 1998 y que, como hemos reiterado, fue eliminado en 2001, flexibilizando de manera excesiva el cumplimiento de requisitos para que los paraísos fiscales fueran eliminados de la lista negra.

\section{Abordar los retos de la economía digital para la imposición (Acción 1)}

Hablar de economía digital es bastante complejo tal como lo reconoce la misma OCDE, y lo es, debido a las constantes reestructuraciones de los grupos multinacionales que les permiten una fácil movilidad de una jurisdicción a otra. Por ello, mediante esta Acción se plantea revisar y analizar las dificultades, tanto en la imposición directa como indirecta, a través de la presencia digital significativa de bienes y servicios que está teniendo lugar en los últimos años. Se trata de identificar a todos los agentes que intervienen en la cadena de valor de la economía digital y desentrañar si en determinado Estado podría considerarse la presencia de un establecimiento permanente al que se pudieran atribuir beneficios empresariales, dado que la intermediación a través de las cadenas de participaciones de sociedades dificulta esa posibilidad.

La preocupación de los Estados de residencia y de fuente, pero en especial de estos últimos, va en aumento, ante la reducción de la base imponible y, por tanto, de la recaudación sobre todo en materia del impuesto sobre sociedades, cuya disminución no se debe solo a la crisis económica y financiera como podría pensarse, sino, más bien, a la utilización de prácticas de planificación fiscal agresiva donde es frecuente el uso de los vacíos en la normativa interna cuando esta interactúa con otras legislacio- nes (a través de los convenios bilaterales o convenios para evitar la doble imposición). Esto lo hacen mediante la estructuración de bases artificiales, cuyo efecto final es la generación de dobles exenciones que permiten una baja o nula tributación, de manera que el objetivo inicial de la tributación internacional, que era evitar la doble imposición, se ha desdibujado facilitando la doble no imposición.

Como mencionamos supra, la disminución de la base imponible que afrontan muchos Estados ha sido ocasionada en menor escala por la crisis económica y en mayor medida por las maniobras de triangulación de operaciones que permiten el traslado de beneficios a jurisdicciones con baja o nula imposición. Compañías como Google, iTunes, Amazon y Facebook alcanzaron ventas por valor superior a los dos billones de euros en Francia, pero su tributación apenas llegó a los cuatro millones de euros por concepto de impuesto sobre beneficios. Este es solo un ejemplo por país, porque situaciones similares se observan en el Reino Unido, España, Estados Unidos (EE.UU.) y Japón, entre otros (Diehl, Google vs. French Taxes, 2013). Esta baja imposición la consiguen a través de la estrategia de localizar sus activos intangibles (marcas, patentes, logotipos, algoritmos, etc.) en jurisdicciones con baja tributación o regulaciones flexibles que facilitan el traslado de beneficios a los paraísos fiscales y crear en otros países con mayores tasas de imposición, compañías que pagan el derecho al uso de esos intangibles, lo que se conoce como royalties o regalías (Digital Trade in the U.S. and Global Economies, 2013, 4). En razón a que el precio de estos activos es intrínsecamente complejo de fijar, se facilita la manipulación de los precios de transferencia, reduciendo aproximadamente 
en un 30\% la recaudación sobre el impuesto de sociedades (Clausing, 2011, 1.580).

El traslado de beneficios entre empresas del mismo grupo económico, cuyas operaciones se desarrollan sobre todo a través de Internet, resulta menos complejo que en el caso de las empresas tradicionales, lo que lleva a plantearse que no es práctico ni eficiente regular las operaciones de las "empresas digitales" mediante la normativa actual, sino que se precisan reglas de tributación diferentes, adaptadas a los desafíos que este nuevo esquema comercial exige, donde aducir la presencia física significativa como elemento para gravar al contribuyente cae en desuso y propicia la planificación fiscal agresiva que tanto mengua la recaudación fiscal de los Estados, cuyas pérdidas se estiman en 130.000 millones de euros en 2013 (Zucman, 2014, 61).

La OCDE ha indicado que uno de los objetivos fundamentales que se propone con esta Acción es identificar las principales dificultades que plantea la economía digital a la aplicación de las actuales normas impositivas internacionales y desarrollar opciones detalladas para abordar estas dificultades con un enfoque holístico y considerando tanto la imposición directa como la indirecta. Por tanto, nuestra consideración es que la principal tarea a ejecutar es la reestructuración de las actuales normas de tributación internacional que no solo propendan a evitar la doble tributación, sino que permitan la eliminación de la doble no imposición, procurando con ello que las gigantes de este sector, como Amazon, Apple, Facebook, Google, Microsoft, Verizon, IBM, Oracle, ATT, Intel, eBay o Yahoo, que utilizan esquemas triangulares agresivos de optimización fiscal, sean sometidas a una tributación real y efectiva en el país de origen de sus beneficios.
Resulta necesario mencionar que si bien el enfoque de trabajo prioritario es hacia el sector de economía digital, no deben perderse de vista en dicha revisión los entramados fiscales para planificación fiscal agresiva de las grandes empresas de la economía tradicional que, en menor escala, también participan de la economía digital, como General Electric, Procter \& Gamble, Johnson \& Johnson, Pfizer, Coca-Cola, Merck, Pepsico, Exxon Mobil, Chevron y aquellas que están en medio de ambas economías, en especial los grandes bancos, como J.P. Morgan, Bank of America o Citigroup (Ibercampus, $<$ http://www.ibercampus.es/la- tributacionde-11-de-14-mayores-multinacionales-inferior-al-4-28631.htm).

\section{Combatir las prácticas tributarias perniciosas, teniendo en cuenta la transparencia y la sustancia (Acción 5) (OCDE/G20 2014)}

Lo que se pretende con esta Acción es revitalizar el trabajo que se viene realizando desde 1998 y expandirlo hacia países que no forman parte de la OCDE, siendo fundamental repensar los criterios que se han tenido en cuenta para declarar a un régimen fiscal como preferencial o perjudicial y reconducir esos criterios a la sustancia económica y a la transparencia. En este Plan de Acción se promueve la transparencia mediante el intercambio automático de información, la confidencialidad y la profundización de las obligaciones de información y documentales ligadas con las operaciones vinculadas. El objetivo es contrarrestar las prácticas tributarias perjudiciales en actividades económicas con mayor movilidad, como las financieras, y otras actividades de servicios, incluidas las de provisión de intangibles, 
actividades cuya naturaleza facilita su traslado de un país a otro. Es pertinente indicar que esta Acción todavía está en proceso de construcción, por lo que nuestros planteamientos estarán condicionados por esta circunstancia.

La propuesta de la OCDE deja claro que se pretende mantener la competencia fiscal, pero se busca que esta sea justa, evitando que algunas jurisdicciones afecten la recaudación de otras mediante la aplicación de prácticas fiscales perniciosas. Esto explica en gran medida que se retome la actividad sustancial como elemento clave para evitar que los beneficios sujetos a imposición se puedan artificialmente desplazar del país donde se han generado efectivamente. "La meta del trabajo de la OCDE en el área de las prácticas fiscales perjudiciales es garantizar la integridad de los sistemas fiscales abordando las cuestiones planteadas por los regímenes aplicables a las actividades móviles y que injustamente erosionan las bases imponibles de otros países y potencialmente distorsionan la localización de capitales y servicios [...] el trabajo es sobre la reducción del efecto distorsionador de la tributación sobre la localización de las actividades financieras y de servicios móviles, fomentando así un ambiente en el cual tenga lugar una competencia fiscal libre y justa" (OCDE/G20 2014).

Las acciones de la OCDE se enfocan en los regímenes fiscales preferenciales, con énfasis en los regímenes de intangibles y de propiedad intelectual (PI), los cuales, además de ser claves para el crecimiento económico y la generación de empleo, con frecuencia son utilizados por las multinacionales como estrategia para disminuir su carga tributaria. La valoración de los regímenes preferenciales que se propone en este plan contempla tres aproximaciones. La primera es la crea- ción de valor; por consiguiente, se espera que los contribuyentes realicen un número significativo de actividades de desarrollo. La segunda corresponde a los precios de transferencia, que no será utilizado como el enfoque de vínculo a pesar de la percepción positiva que muchos Estados miembros tienen de este, pues suscita la preocupación de que contraríe algunas legislaciones, en particular la de la UE.

La tercera aproximación funciona como vínculo o nexo. Mediante este, se pretende verificar si los regímenes de PI condicionan sus beneficios a las inversiones en investigación y desarrollo, siguiendo el modelo de los regímenes tributarios front-end, en los cuales, los gastos y los beneficios están directamente relacionados porque los gastos se utilizan para calcular el impuesto sobre beneficios. Esta aproximación enfocada en los gastos tiene como propósito «conectar» los beneficios con los gastos en que se incurre para obtenerlos, es decir, considera los gastos como proxy de la existencia de actividad sustancial. Es importante aclarar que no se utiliza el valor de los gastos como indicador directo de los ingresos sino su proporción como elemento para demostrar el valor añadido real de las actividades realizadas por el contribuyente y, por consiguiente, para conocer qué tanta actividad sustancial ha desarrollado. Aunque se propone una fórmula para calcular la proporción de los ingresos que deben gozar de beneficio, también se indica que se podrían permitir exoneraciones mayores si se incurre en gastos superiores y se demuestra el vínculo entre éstos y los ingresos.

La segunda prioridad de esta Acción y uno de los aspectos más destacables es su apuesta por la transparencia a través del intercambio automático y obligatorio de in- 
formación sobre resoluciones relacionadas con los regímenes preferenciales. Se trata de un nuevo direccionamiento que no se centra en los regímenes perjudiciales o potencialmente perjudiciales como lo hacía en el pasado, sino que se enfoca en los regímenes preferenciales. Lo que se pretende es que el país afectado disponga de información oportuna (en un plazo no superior a tres meses) y relevante sobre acuerdos preferenciales en precios de transferencia o en cualquier otra área. Aunque la guía está en proceso de construcción, ya incorpora los elementos mínimos que debe compartir el país que otorga las exenciones, dependiendo del tipo de acuerdo preferencial del que se trate. En esta Acción aún está por terminar la revisión de los regímenes actuales, con el ánimo de establecer si estos son perjudiciales, potencialmente perjudiciales o simplemente preferenciales. En todo caso, en el informe de progreso que debe presentarse en diciembre de 2015, deberá quedar constancia de los hallazgos.

Tres elementos adicionales hacen aún más interesante esta propuesta de intercambio automático de información. El primero es la importancia que se le confiere a la retroalimentación como estrategia para mejorar el intercambio futuro. El segundo es la exigencia de confidencialidad; por un lado, se espera que el país receptor la garantice en relación con el contribuyente y con el país proveedor de la información y, por otro, se establece que esta solo pueda utilizarse con fines fiscales u otros que sean permitidos. El tercero es la instrucción a los países para que, de ser necesario, ajusten su normativa con el fin de garantizar la aplicación del marco de intercambio automático de información.

La propuesta descrita representa un avance importante en aras de lograr una mayor transparencia entre los sistemas tributarios y por consiguiente, una estrategia necesaria en la lucha contra los paraísos fiscales. Aunque no constituye en sí misma la solución para abolir los regímenes perjudiciales, sí es un complemento indispensable para lograrlo. Sin embargo, y sin ánimo de esbozar una postura pesimista, será necesario esperar algunos años para ver los resultados y comprobar que estas ideas en principio tan valiosas, se pueden llevar a la práctica y no se ven desechadas debido a los intereses particulares de algunos Estados miembros de la OC$\mathrm{DE}$, como ya sucedió en años anteriores con otras propuestas que, en su momento, eran igualmente importantes y necesarias para combatir las prácticas fiscales perniciosas.

\section{Contradicción entre la formalidad y la materialidad de los paraísos fiscales}

\section{La formalidad de los paraísos fiscales}

Parece que desde estos mismos territorios se ha creado una estrategia para dejar atrás el apelativo de "paraíso fiscal" y tomar el de "centro de servicios financieros offshore", aunque en la práctica, su funcionamiento y efectos lesivos son los mismos. Así lo confirma la Note d'analyse 222 - Centres financiers offshore et système bancaire "fantôme" (que en español podría traducirse como "sistema bancario en la sombra") presentada por el Centro de Análisis Estratégico de París, en la que se denuncia la rápida evolución de los paraísos fiscales y su conversión a centros offshore (Note d'analyse 222 - Centres financiers offshore et système bancaire "fantôme"). En ella se incluyen, entre otros aspectos, el concepto de paraíso fiscal, la conexión y complementariedad existente entre los paraísos fiscales y los centros financieros 
offshore, y la integración financiera de los centros financieros offshore y la propagación del riesgo sistémico, tal como lo expone Gutiérrez de Pablo (2013, 57).

Lo más preocupante es que estos centros financieros offshore procuran dar la apariencia de legalidad, para lo cual suelen utilizar algunos tipos de entidades y programas, como son las compañías de seguros cautivas y reaseguros, los préstamos entre vinculados, los fideicomisos o trusts en el extranjero, las sociedades en el extranjero, las sociedades offshore y offshore privadas, las cuentas bancarias offshore, las sociedades de responsabilidad limitada ( $L L C S$ y $L L P S$ ), las compañías internacionales de negocios (IBCS), las empresas de inversión personal y las tarjetas de crédito. A través de estos servicios se crean estructuras o entramados fiscales que, en el fondo, lo que permiten es una planificación fiscal agresiva.

Como ya hemos expuesto, para la OCDE no existe en la actualidad ninguna jurisdicción clasificada en la lista negra de paraísos fiscales, gracias a que quienes estaban en ella se han comprometido a cumplir las tímidas exigencias formales. Con ello, se ha demostrado que fueron formalidades tan frágiles que han sido traspasadas por la materialidad de los fondos que circulan en estas jurisdicciones en detrimento de la recaudación fiscal, como lo expondremos en el apartado siguiente. Es oportuno mencionar que en la reunión del Foro Global celebrada en Berlín en 2014, se publicó una lista en la que se muestra el grado de cumplimiento de la norma de intercambio de información fiscal por parte de las distintas jurisdicciones. En ella, se indica que Andorra, Anguila, Antigua y Barbuda, Austria, Barbados, Curazao, Indonesia, Israel, Santa Lucía y Turquía cumplen parcialmente dicha norma, mientras que las jurisdicciones que no la cumplen son Chipre, Luxemburgo, República de Seychelles e Islas Vírgenes Británicas (OCDE, Foro Global, 2015). Vemos cómo se les da el calificativo de jurisdicción "no conforme" y se evita llamarles lo que realmente son, esto es, paraísos fiscales, reiterando nuestra posición de que formalmente ya no existen, pero qué decir de su existencia material. El hecho de que persista tal apatía al intercambio de información debería como mínimo generar inquietud y suscitar el debate respecto de la transparencia informativa y la voluntad de cooperación por parte de esas jurisdicciones que, como hemos mencionado, se convierten en una amenaza para otras jurisdicciones y para el contribuyente que no dispone de medios o no desea ejecutar una planificación fiscal agresiva.

\section{La materialidad de los paraísos fiscales}

Desde el inicio de esta investigación hemos llamado la atención sobre los abultados fondos que se depositan en estos territorios o que circulan de un lugar a otro, siempre en busca de una nula o baja tributación. Nos atrevemos también a repetir cifras como los 130.000 millones de euros de pérdida en recaudación fiscal para todos los Estados del mundo, o que entre el $10 \%$ y el $11 \%$ de todas las riquezas, es decir, ocho billones de euros, están ocultos en paraísos fiscales; que el $80 \%$ de las fortunas offshore no están declaradas, lo que equivale a 4,7 billones de euros en 2013 (Zucman, 2014, 62). Estas cifras hablan por sí solas de la profunda crisis fiscal mundial actual, sin que los grandes grupos multinacionales que participan directamente de ella tengan escrúpulo moral con los Estados donde realmente obtienen los ingresos y de los cuales utilizan sus infraestructuras e instituciones. 
España no es ajena a la realidad descrita en este trabajo. Así lo confirma la $10^{a}$ edición del informe "La Responsabilidad Social Corporativa en las memorias anuales de las empresas del IBEX 35" de 2012, en el cual se ha indicado, entre otros asuntos, que las empresas listadas en el IBEX 35 omiten riesgos en sus memorias y operan, salvo dos de ellas, en paraísos fiscales. Deja claro que el $94 \%$ de dichas compañías participaban en empresas o sociedades domiciliadas en paraísos fiscales en 2012. En concreto, el informe se refiere a las siguientes empresas: Abengoa, Abertis, Acciona, Acerinox, ACS, Amadeus, Arcelor Mittal, Bankia, Bankinter, BBVA, Banco Popular, Banco Sabadell, Banco Santander CH, Bolsas y Mercados, Caixabank, Dia, Enagas, Endesa, FCC, Ferrovial, Gamesa, Gas Natural, Grifols, Iberdrola, IAG Iberia, Inditex, Mapfre, OHL, Red Eléctrica, Repsol, Técnicas Reunidas, Mediaset y Telefónica (IBEX, Informe 35, 2015).

A la lucha formal de la OCDE y el G20 contra los paraísos fiscales mediante el plan Harmful Tax Competition hasta 2012 y, a partir de 2013, mediante el Plan de Acción BEPS, cuyos primeros resultados se conocieron en diciembre de 2015, se contrapone el criterio auxiliar de la reputación internacional o fama mundial para identificar a un paraíso fiscal como tal. Una sencilla demostración de ello es que en un motor de búsqueda como el mismo Google se obtuvieron los siguientes resultados: ingresando la búsqueda en idioma español Paraísos Fiscales, en 0,39 segundos aparecieron cerca de 1.110.000 resultados; en idioma francés Paradis Fiscal, en 0,61 segundos se desplegaron 544.000 referencias, y en idioma inglés Tax Havens, en tan solo 0,37 segundos surgieron alrededor de 2.040.000 resultados: todos se refieren a enlaces en los que aparecen jurisdicciones o territorios reseñados como tal, lo que encuadra perfectamente con el criterio auxiliar de reputación. Es el caso de jurisdicciones como Suiza, Liechtenstein, la Isla de Jersey, las Islas Caimán, Andorra, Gibraltar, las Bermudas, Luxemburgo, Panamá y, recientemente, Turquía, entre otros.

Para finalizar lo que respecta a la materialidad, presentamos las tablas 1 y 2 , en las cuales es posible apreciar los datos sobre la tributación directa e indirecta de 11 de las 14 mayores multinacionales pertenecientes a los sectores de la economía digital, la economía tradicional y aquellas que están en medio de ambas, como son los bancos. Las cifras absolutas y los porcentajes disponibles en ellas, ratifican la existencia de una profunda contradicción entre la formalidad y la materialidad de los paraísos fiscales. 


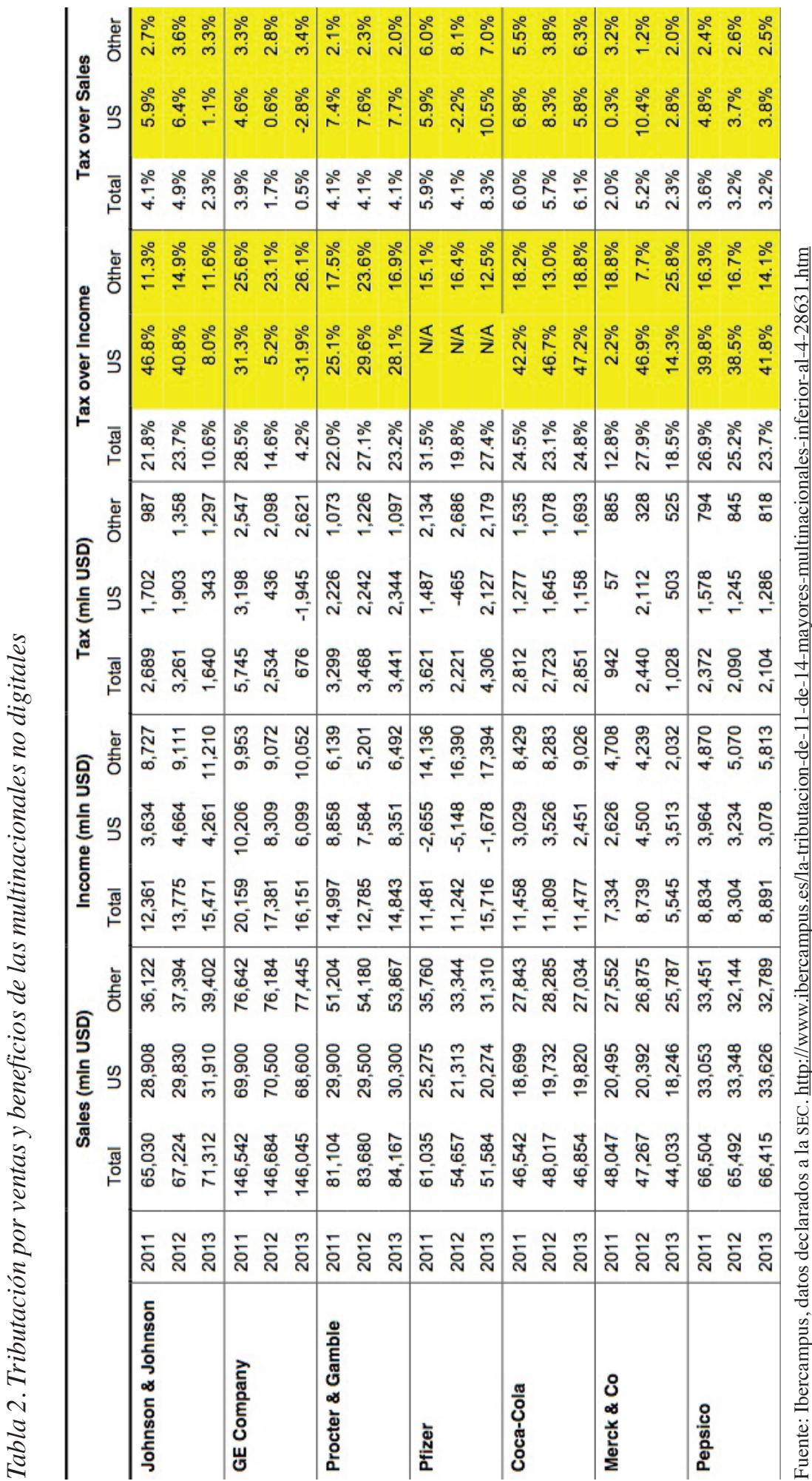




\section{Reflexión sobre el estado actual de la cuestión}

Ya hemos apuntado la magnitud de las cifras que circulan por los paraísos fiscales, las cuales se mantendrán o aumentarán en la medida que algunos de los países desarrollados y otros en vías de desarrollo permitan la existencia de estos paraísos en sus propios territorios o poseyendo territorios asociados a su jurisdicción calificados de esta manera. Poco o nada efectivas resultarán las medidas defensivas o conciliadoras lanzadas por la OCDE y G20 para contrarrestarlos; per se, seguirá existiendo el socavamiento de la recaudación fiscal en tanto no se establezcan medidas multilaterales de carácter global y consensuadas eliminando cualquier interés oculto de los Estados.

Vistas las acciones que se han adelantado hasta el momento, nos arriesgamos a plantear que falta mucho por hacer para la consecución del ansiado terreno de juego fiscal justo y equilibrado, en el cual exista una retribución adecuada para todos los Estados sin discriminación alguna, pues los paraísos fiscales seguirán existiendo incluso dentro de la OCDE y de la UE. La erosión de la base imponible y el traslado de beneficios hacia ellos continuará en aumento, por lo que una verdadera acción debería enfocarse, por un lado, en replantear los actuales criterios establecidos para catalogar a un Estado o jurisdicción como paraíso fiscal y, por otro, en la estructuración de una norma que obligue al desmantelamiento del secreto bancario y al intercambio automático de información financiera y tributaria.

Nos resulta difícil creer que en un futuro cercano se logrará la eliminación de los paraísos fiscales o siquiera su declive, cuando es evidente la brecha entre el discurso y su ejecución. En la cumbre anual del G20 celebrada en Cannes los días 3 y 4 de noviembre de 2011, el presidente de turno de esta organización, el entonces Presidente de la República Francesa, Nicolás Sarkozy, hizo unas duras declaraciones sobre los paraísos fiscales en la rueda de prensa al final de la cumbre:

(n)o queremos más paraísos fiscales. El mensaje es muy claro [...] Los países que sigan siendo paraísos fiscales con el disimulo financiero serán condenados al "ostracismo por la comunidad internacional", anunciando que el G20 realizará en sus cumbres una "publicación sistemática" de la lista de "países que no hacen lo que hay que hacer para acabar con un comportamiento inadmisible" (Declaración final de la Cumbre del G20, 2011).

Han pasado más de tres años desde las citadas declaraciones y las cifras asociadas a los paraísos fiscales no muestran mejoras significativas. De hecho, si se analizan los datos publicados por Tax Justice Network sobre el índice de secreto financiero, se puede apreciar que entre 2011 y 2013 no hubo una disminución de los fondos opacos, sino una redistribución de estos entre un mayor número de jurisdicciones. Adicionalmente, se observa que nueve de las diez jurisdicciones que encabezaban el listado en 2011 lo hicieron también en 2013.

Antes de finalizar 2011, ya se validaba que en la llamada lista negra de paraísos fiscales de la OCDE no aparecía ningún Estado o jurisdicción, pero sí en la lista gris, donde 11 jurisdicciones (Antigua y Barbuda, Barbados, Botsuana, Brunei, Liechtenstein, Panamá, República Seychelles, Suiza, Trinidad y Tobago, Uruguay y Vanuatu) con- 
tinuaban siendo objeto de vigilancia hasta que completaran la implementación y aplicación total de las normas internacionales de intercambio efectivo de información y transparencia de sus sistemas (Declaración final de la Cumbre del G20, 2011). Sin embargo, aunque la lista negra no contenga nombre alguno, se aprecia que persisten las operaciones opacas gracias a la flexibilidad de legislaciones fiscales de aquellas jurisdicciones que se han reputado internacionalmente como paraísos fiscales, entre ellos Suiza, Liechtenstein, Jersey, Islas Caimán, Andorra, Gibraltar, Bermudas, Luxemburgo, los Estados de Delaware y Nevada (EE.UU.), Islas Vírgenes (británicas y americanas), Singapur (China) y Estados como Holanda, Hungría, Dinamarca y Turquía. Es lamentable que los intereses políticos de algunos Estados primen sobre las necesidades internacionales generales y que, con solo firmar 12 acuerdos de intercambio de información, la OCDE traslade a esa jurisdicción a la lista blanca, cuando los problemas básicos que son el menoscabo de la recaudación fiscal, la erosión de la base imponible y el traslado de beneficios ocasionados por la competencia fiscal perniciosa continúan vigentes.

En el fondo, esos territorios fiscalmente atractivos y opacos son el foco principal de la evasión y la elusión fiscales de orden internacional, generando efectos lesivos que no son tenidos en cuenta por los grupos multinacionales inmersos en la planificación fiscal agresiva por considerar que se ajustan a la ley. Esta situación pone de relieve que las normas internacionales de tributación se han quedado obsoletas y no hacen frente a la nueva era de economía global y en su mayor parte digital. Tanto los países desarrollados como los no desarrollados sufren la disminución de sus ingresos tributarios, pero con mayor rigor los últimos, que según estimaciones de la Organización Británica Christian Aid pierden unos 160.000 millones de dólares anualmente por causa de la evasión y elusión fiscales. En tanto, en 2007, el Banco Mundial ha respaldado las estimaciones de Global Financial Integrity (GFI), según las cuales el flujo transfronterizo de los ingresos globales de las actividades delictivas, la corrupción y la evasión fiscales en dólares de los EE.UU. al año van de $\$ 1$ hasta $\$ 1.600$ mil millones, la mitad de países en desarrollo y economías en transición. En 2009, la investigación de GFI actualizada estima que anualmente los flujos transfronterizos de los países en desarrollo solo ascienden aproximadamente a $\$ 850$ mil millones EE.UU. $\$ 1,1$ billón por año (Owens, 2009).

Los países desarrollados también sufren las consecuencias de estas conductas. Se calcula que la evasión fiscal en los EE.UU. asciende a 100 billones de dólares y que los paraísos le cuestan a la economía mundial entre 21 y 32 trillones de dólares al año (Tax Justice Network, Inequality: You Don't Know the Half of It, 2012).

No podemos terminar esta reflexión sin advertir que la Cumbre de Líderes del G20 llevada a cabo los días 18 y 19 de junio de 2012 en Los Cabos, México, se centró más en la crisis financiera de la Eurozona que en cualquier otro asunto de igual relevancia inclusive. Escasamente, en la declaración final (Declaración de líderes del G20, 2015) se hizo la siguiente mención a los paraísos fiscales y al secreto bancario: "(a)cogemos el avance del GAFI al identificar y monitorizar las jurisdicciones de alto riesgo con deficiencias estratégicas de Prevención de Lavado de Dinero y del Financiamiento al Terrorismo, utilizando las herramientas para abatir la corrupción, mejorar la trans- 
parencia de los instrumentos corporativos e incrementar la cooperación en el combate de los delitos fiscales, atajando los riesgos que representan los paraísos fiscales". Teniendo en cuenta que los paraísos fiscales han contribuido directamente a la generación de la crisis financiera que ocupó gran parte de la agenda en la citada cumbre, su eliminación debe convertirse en un incansable objetivo de organizaciones internacionales como la OCDE, el G7/G8, el G20, la UE y cualesquiera otras y, sobre todo, debe configurarse no solo como un fin formal o político, sino como un objetivo real, aplicándose las vías de toda índole, incluso la sancionatoria.

Por ahora, queda esperar los resultados del Plan de Acción BEPS. Sin embargo, y sin perjuicio de otras opiniones, consideramos que el trabajo allí propuesto para contrarrestar la competencia fiscal perjudicial tiene pocas posibilidades de éxito si se conduce de manera similar al proyecto iniciado en 1998, que procuraba la eliminación de los paraísos fiscales antes de finalizar 2005 y del cual la misma OCDE admitió su fracaso en la cumbre de Londres 2009. Con ello queremos advertir que mientras persista una normativa cuya aplicación sea voluntaria y no vinculante y se sigan anteponiendo los intereses político-económicos de unos pocos a las necesidades comunes globales, los resultados no pueden ser otros que la flexibilización de requisitos para evitar el señalamiento como jurisdicción con régimen fiscal perjudicial; la continuidad de la fuga de capitales a esos territorios en detrimento de la recaudación fiscal de otros Estados, cuyos sistemas fiscales se tornarán inequitativos debido al traslado de la carga tributaria sobre los ciudadanos comunes y, por último, una ampliación de la brecha de desigualdad económica (Tax Jus- tice Network, Inequality: You Don't Know the Half of It, 2012).

\section{Conclusiones}

Los datos presentados por las ONG e investigadores independientes dan cuenta de la magnitud de las cifras que circulan por los paraísos fiscales y los centros de servicios financieros offshore (que en el fondo son lo mismo). Esas jurisdicciones mueven cantidades asombrosas de dinero ligadas a diversas actividades non sanctas que van desde la elusión y la evasión fiscales hasta el lavado de activos, la corrupción política y el terrorismo, entre otras, generando, como es de esperar, nocivas consecuencias para los Estados y para los ciudadanos. Sobre los primeros se produce un socavamiento de los ingresos fiscales y, con ello, una pérdida en la recaudación fiscal, que no les permite cumplir con los fines públicos. En el caso de los segundos, se ven sometidos a una mayor presión fiscal, al tener que soportar mayores impuestos producto de las deslocalizaciones de los beneficios de aquellas rentas más móviles hacia esos territorios, lo que rompe el principio internacional de justicia fiscal. Para ambos, porque el blanqueo de capitales, la financiación del terrorismo, la opacidad financiera y la corrupción se convierten en instrumentos delictivos más que suficientes para romper cualquier sistema político estable.

Queremos también enfatizar en la profunda contradicción existente entre la formalidad y la materialidad de los paraísos fiscales, lo cual nos motivó para adelantar esta investigación, con la cual queremos hacer un llamado a la academia, la sociedad, los entes económicos $\mathrm{y}$, sobre todo, a los organismos internacionales y a los Estados, para que realicen un examen profundo de las normas 
internacionales de fiscalidad, cuya laxitud ha contribuido para que dichos territorios pasen de ser denominados paraísos fiscales a jurisdicciones "no cooperantes" o "no conformes" y cuya posibilidad de alcanzar la calificación de "conforme en alto grado" o "plenamente conforme" es muy alta porque las exigencias para ello se centran básicamente en la firma de acuerdos para el intercambio de información, de los cuales no hay a la fecha estudios o investigaciones que contengan evidencia de su efectividad.

Cuando nos referimos a esa contradicción, ya desde lo material, sin reproducir las cifras previamente indicadas en esta investigación, debemos advertir que mientras no existan normas claras, efectivas y, sobre todo, vinculantes de transparencia fiscal internacional e intercambio efectivo y multilateral de información fiscal, estos territorios continuarán siendo el agujero negro del sistema financiero y económico. Las normas meramente formales que hoy están vigentes son el paso a esta materialidad socialmente indeseable, en la que los expertos contables, financieros y fiscales están al día en los vacíos jurídicos de la normativa para asesorar a personas jurídicas y físicas, sin dejar rastro de incumplimiento legal, en gran medida gracias a que las actuales normas de fiscalidad internacional permiten la creación de entramados fiscales, los abusos del derecho y la planificación fiscal agresiva. El cuestionamiento en este punto no es si se trata de acciones legales, sino que las personas implicadas en estos comportamientos no hacen un juicio de lo moral y lo justo respecto de lo que deberían tributar, aprovechándose, en las mismas condiciones que los demás ciudadanos cumplidores de la ley fiscal, de las infraestructuras, servicios públicos y entidades del Estado, comportándose como verdaderos free riders.

También llama nuestra atención que los actuales trabajos, por ejemplo, de la OCDE y el G20 para contrarrestar las prácticas fiscales perniciosas a través del Plan de Acción BEPS, tienen objetivos y resultados trazados a fechas ciertas, pero su efectividad no se aprecia tan clara, en tanto sigan siendo normas supeditadas a la voluntad política de los Estados y mientras no se aborden problemas de fondo de las normas de fiscalidad internacional, como la residencia, la potestad tributaria para gravar los beneficios trasladados y la transparencia fiscal internacional.

El escenario descrito nos lleva a sugerir que la solución al problema actual de la tributación internacional y, más concretamente, la eliminación de los paraísos fiscales, debe ser global y contar con el apoyo de todos los países que ven erosionada su base imponible, sea que pertenezcan o no a organizaciones o comunidades como la OCDE, la ONU (Organización de Naciones Unidas), el G20 o la UE, las que tradicionalmente han liderado diversas propuestas en esta área. Esperemos que las buenas acciones propuestas sean el inicio de una nueva era de la fiscalidad internacional, en la que finalmente se ataque la doble no imposición y, así, los Estados puedan cumplir sus fines públicos. 


\section{Referencias}

\section{Bibliográficas}

Botello Machín, V. y Palacios Pérez, J. (2005). “Introducción a la planificación fiscal internacional”, en Serrano Antón, F. (dir.): Fiscalidad Internacional, $2^{\mathrm{a}}$ ed. Madrid: Centro de Estudios Financieros.

Carrasco Parrilla, P. J. (2011). "La armonización fiscal en la Unión Europea”, en Collado Yurrita, M. A. (dir). Intercambio Internacional de Información Tributaria. Avances y proyección futura. Navarra: Thompson-Aranzadi.

Ferre Navarrete, M. (2007). "Los paraísos fiscales y las medidas antiparaíso", en Manual de Fiscalidad Internacional, Cordón Ezquerro, T. (dir.), $3^{\mathrm{a}}$ ed. Madrid: Instituto de Estudios Fiscales.

Fischer, J.M. y Fairer Shores (2014). “Tax Havens, Tax Avoidance, and Corporate Social Responsibility”, en Boston University Law Review, Vol. 94.

García Noriega, A. (s.f.). Blanqueo y antiblanqueo de capitales, $3^{\text {a }}$ ed. Madrid: Difusión Jurídica y Temas de Actualidad S.A.

Gutiérrez de Pablo, G. (2013). "Bancos offshore: diversos aspectos sobre su utilización a través de instrumentos financieros", en Cuadernos de formación del Instituto de Estudios Fiscales, Vol. 16, n. ${ }^{\circ} 3$.

Hernández Vigueras, J. (2005). Los paraísos fiscales: cómo los centros offshore socavan las democracias. Madrid: Ediciones Akal S.A.

Johannesen, N. y Zucman, G. (2014). "The End of Bank Secrecy? An Evaluation of the G20 Tax Haven Crackdown", en American Economic Journal: Economic Policy, n. ${ }^{\circ} 6$.

Martín López, J. (2006). Competencia fiscal perjudicial y ayudas de Estado en la Unión Europea. Valencia: Tirant Lo Blanch.

Martínez Selva, J.M. (2009). Los paraísos fiscales. Uso de las jurisdicciones de baja tributación. Madrid: Ediciones Jurídicas DIJUSA.

Marulanda Otálvaro, H. (2013). Competencia fiscal perniciosa entre Estados. Medellín: Centro de Estudios Tributarios - CETA.

Merino Espinosa, M. D. P., y Nocete Correa, F. J. (2011). "El intercambio de información tributaria: entre la diversidad normativa, la imprecisión conceptual y la pluralidad de intereses", en Crónica tributaria, n. ${ }^{\circ} 139$.

Rodríguez Santos, F.J. (2005). "Planificación fiscal internacional. Los paraísos fiscales", en Estudios sobre fiscalidad internacional y comunitaria, Collado Yurrita, M. (dir.). Madrid: Ed. Constitución y Leyes S.A.

Schjelderup, G. (2015). Secrecy Jurisdictions - Working Paper.

Serrano Palacio, C. y García Villanova Ruiz, I. (2008). "Competencia fiscal perniciosa. Estado actual de la normativa española y el caso holandés", en Cuadernos de formación del IEF n. 34.

Szarmach, L. (2010). "Piercing the Veil of Bank Secrecy? Assessing the United States' Settlement in the UBS Case”, en Cornell International Law Journal, Vol. 43.

Vallejo Chamorro, J.M. (2007). “La competencia fiscal”, en Manual de Fiscalidad Internacional, Cordón Ezquerro, T. (dir.), $3^{\mathrm{a}}$ edición. Madrid: Instituto de Estudios Fiscales. 
Winkleman, T.J. (s.f.). "Automatic Information Exchange as a Multilateral Solution to Tax Havens”, en Indiana International \& Comparative Law Review, Vol. 22, n. ${ }^{\circ} 1$.

Zucman, G. (2014). “La riqueza oculta de las naciones. Investigación sobre los paraísos fiscales”, en Pasado \& Presente. Barcelona.

\section{Doctrina especializada}

Financial Secrecy Index 2013. Disponible en http://www.financialsecrecyindex.com/PDF/FSI-Methodology.pdf.

The International Consortium of Investigative Journalists "Secrecy for Sale. Inside the Global Offshore Money Maze. Disponible en http://www.icij.org/offshore o en http://cloudfront-files1.publicintegrity.org/documents/ pdfs/ICIJ\%20Secrecy\%20for\%20Sale.pdf. Consultados el 6 de marzo de 2015.

Documento de la OCDE de 1998 "Harmful Tax Competition. An Emerging Global Issue. Disponible en http:// www.oecd.org/tax/transparency/44430243.pdf Consultado el 9 de abril de 2015.

Documento del FMI de 2011 “Revenue Mobilization in Developing Countries”, pág. 39. Disponible en http:// www.imf.org/external/spanish/np/pp/2011/030811s.pdf. Consultado el 9 de marzo de 2015.

Documento de la OCDE de 2001 "The OECD's Project on Harmful Tax Practices: The 2001 Progress Report". Disponible en http://www.oecd.org/ctp/harmful/2664450.pdf. Consultado el 9 de abril de 2015.

Documento de la OCDE de 2004 "The OECD's Project on Harmful Tax Practices: The 2004 Progress Report". Disponible en http://www.oecd.org/ctp/harmful/30901115.pdf. Consultado el 9 de abril de 2015.

Documento de la OCDE de 2012 "Global Forum OECD the Global Forum on Transparency and Exchange of Information for Tax Purposes”. Disponible en http://www.oecd.org/ctp/harmful/43757434.pdf. Consultado el 9 de abril de 2015.

Documento de la OCDE de 2013 “Action Plan on Base Erosion and Profit Shifting”. Disponible en http://www. oecd-ilibrary.org/docserver/download/2313331e.pdf?expires=1428743583\&id=id\&accname =guest\&checksum =2B87852C5A02D587C1925A65F6E62D34. Consultado el 16 de marzo de 2015.

Documento de la OCDE de 2015 del Foro Global titulado "Phase 1 and Phase 2 Reviews (as of March 2015)". Disponible en http://www.oecd.org/tax/transparency/GFratings.pdf. Consultado el 15 de abril de 2015. 